\title{
Optical microscopy analysis of mortars from Tagus River 16th and 17th century fortifications
}

\author{
Teresa Guerreiro ${ }^{*}$, Antonio Santos Silva ${ }^{* *}$, Patricia Adriano ${ }^{* *}$, Antonio Candeias $^{* * *}$, Jose Mirao ${ }^{*}$ \\ *Universidade de Évora, Geosciences Department and Geophysics Center of Évora, Rua Romão \\ Ramalho 59, 7000-671 Évora, Portugal (jmirao@uevora.pt). \\ ** Laboratório Nacional de Engenharia Civil, Materials Department, Av. Brasil 101, 1700-066 \\ Lisbon, Portugal (ssilva@lnec.pt, padriano@lnec.pt). \\ Universidade de Évora, Chemistry Department and Évora Chemistry Center, Rua Romão \\ Ramalho 59, 7000-671 Évora, Portugal (candeias@uevora.pt).
}

Mortars are common and essential elements of masonry historical buildings [1] and are composed by a binder, aggregates and eventually, some additives. The binder provides consistency to this composite material, and until the emergence of Portland cement in the 19th century, lime was the main binder used. The aggregates are normally sand or rock fragments with variable sizes. The whole set is morphologically very similar to a sedimentary clastic rock with carbonate cementing. Following an old tradition of microscope use in this kind of rocks, it is not surprising the application of optical microscopy to mortars [2] as also happened with concrete.

The focus of the study was three 16th/17th century buildings in the Tagus estuary access, the forts of S. Bruno, Bugio and S. Julião da Barra (fig. 1). The S. Bruno Fort is located at the confluence of Barcarena river with Tagus River, near Caxias (Oeiras County). The Fort was ordered by King D. Joao IV in 1647. It is a small fortress with a typical star typology. The S. Julião da Barra Fort is located in Oeiras on the right side of the mouth of Tagus River and facing the sea. Its construction started in the 16th Century by order of King Joao III. During the Filipine Dinasty it was used as state prison and under D. Joao IV was amplified to the present size in order to augment its defensive power. The Bugio Fort is located in a small sand islet (Cabeça Seca Island) at the middle of entrance of Tagus river mouth and is an example of military renascence fortress with circular typology. Its construction started in 1590 by order of King Filipe I and was concluded in 1657. During the 18th Century was used as a prison and a lighthouse was installed to aid navigation. Each sample was collected under supervision of the Portuguese Institute of Architectural Heritage in sites defined by the conservation technicians. The size of each sample was the minimum that could guarantee the success of the analysis and the confirmation for future studies. The mortars were thoroughly observed in laboratory using an Olympus stereo-zoom microscope and carefully disaggregated to avoid breaking the existing aggregates. Thin sections and polished surfaces of the mortars were prepared by vacuum impregnation with an epoxy resin.

Optical microscopy observations were performed in an Olympus petrographic microscope while scanning electron microscopy (SEM) observations were performed in a JEOL JSM-6400 microscope in polished surfaces and thin sections after carbon sputtering and complemented with energy dispersive X-ray Spectrometry (EDS) by an Oxford Inca X-Sight EDS Si(Li) detector. The lime nodules are easily identifiable. Its presence is compatible with a minimum use of water during the slacking process. The carbonate binder is optically very similar to a very fine carbonate rock. The aggregates are homogeneously distributed in the binder, configuring a carbonate cement sandstone texture like (fig. 4 IIIa, IVa, IVb). Occasionally the binder is cut by fractures filled with secondary carbonates. This suggests that the binder suffered contraction after drying (fig. 4 IIa). 
The mortar's aggregate mineralogical composition is compatible with the geological environment of these historic buildings (fig. 1, fig. 2). The quartz is clearly the most abundant mineral (e.g. fig. 4-IIc). Often the grains are rounded (fig. 4), suggesting a long transport or sea erosion action. The regional carbonates are also very relevant minerals in the aggregates. The fossil and shells (fig. 4IIIc, IVc) are also compatible with the abundance of sedimentary rocks and sea closeness. Reduced amounts of certain minerals like feldspars or micas (fig. $4 \mathrm{Vb}$ ) or rock clasts like quartzite (fig. $4 \mathrm{Va}$ ) or sandstone (fig. $4 \mathrm{Id}$ ) were also identified The quartz grains are frequently weathered due to the reaction with the strongly alkaline binder solution.

The "Principle of Compatibility" is one of the main concerns in conservation and restoration activities. In terms of mortars, this means that the new mortars must be physically and chemically similar to the old ones as possible. Especially important is the binder/aggregate ratio, normally calculate by thermoanalytical or diffraction techniques, assuming that all the carbonate corresponds to the binder. Nevertheless this method cannot distinguish the binder from carbonate aggregates. This issue can be corrected by point counting and estimating the ratio of the carbonate aggregates in the total carbonate content. In what concerns to S. Bruno and S. Juliao forts the actual binder content must be reduced by almost a third, if estimated only by thermoanalytical or diffraction techniques, due to the abundance of carbonate aggregates (fig. 2)

The contact between aggregate grains and binder is often filled with neoformation pozzolanic compounds. The SEM-EDS spectra show that these materials are calcium aluminossilicates. It is well known that these compounds improve the hydraulic properties of mortars. This is achieved by addition of minor quantities of unusual substances. However the optical microscopy can enlighten the spatial distribution of the neoformation substances in the binder-aggregate boundary besides some amount in the binder. This textural information supports the hypothesis that the pozzolanic materials fill empty and more friable spaces and so providing better hydraulic properties. The more frequent addictives are highly amorphous volcanic or ceramic materials that provide alumina and silica to a alkaline environment. It is remarkable that nevertheless the proximity of basaltic geological outcrops the builders opted by using ceramic materials (cocciopesto). Some did not react with the mortar along the time and are still observable (fig. 4 Ic, IVa).

The results show that petrographic microscopy is a powerful technique that can give valuable and complementary information. Even though this technique has some difficulties in the identification of minute phases like clay minerals, the spatial information that can offer is unique. Especially important is the visualization of neoformation pozzolanic materials between aggregate grains and binder and the distribution of the aggregates in the binder. The morphology of the sand particles enabled the identification of the source of raw materials as mainly beach sediments. Relatively to $\mathrm{x}$-ray diffraction, microscopy is more sensitive to small quantities and it is essential to accurately determine the aggregates/binder ratio when the aggregates are composed of carbonate lithoclasts.

\section{Acknowledgments}

The work had financial support from FCT and FEDER under project POCI/HEC/57915/2004.

\section{References}

[1] A.S. Silva, J. Ricardo, M. Salta, P. Adriano, J. Mirao \& A.E. Candeias, Heritage, Weathering and Conservation, Taylor \& Francis, Madrid, 2006, 85-90.

[2] J. Elsen, Cem. Concr. Resear., 36 (2006) 1416. 

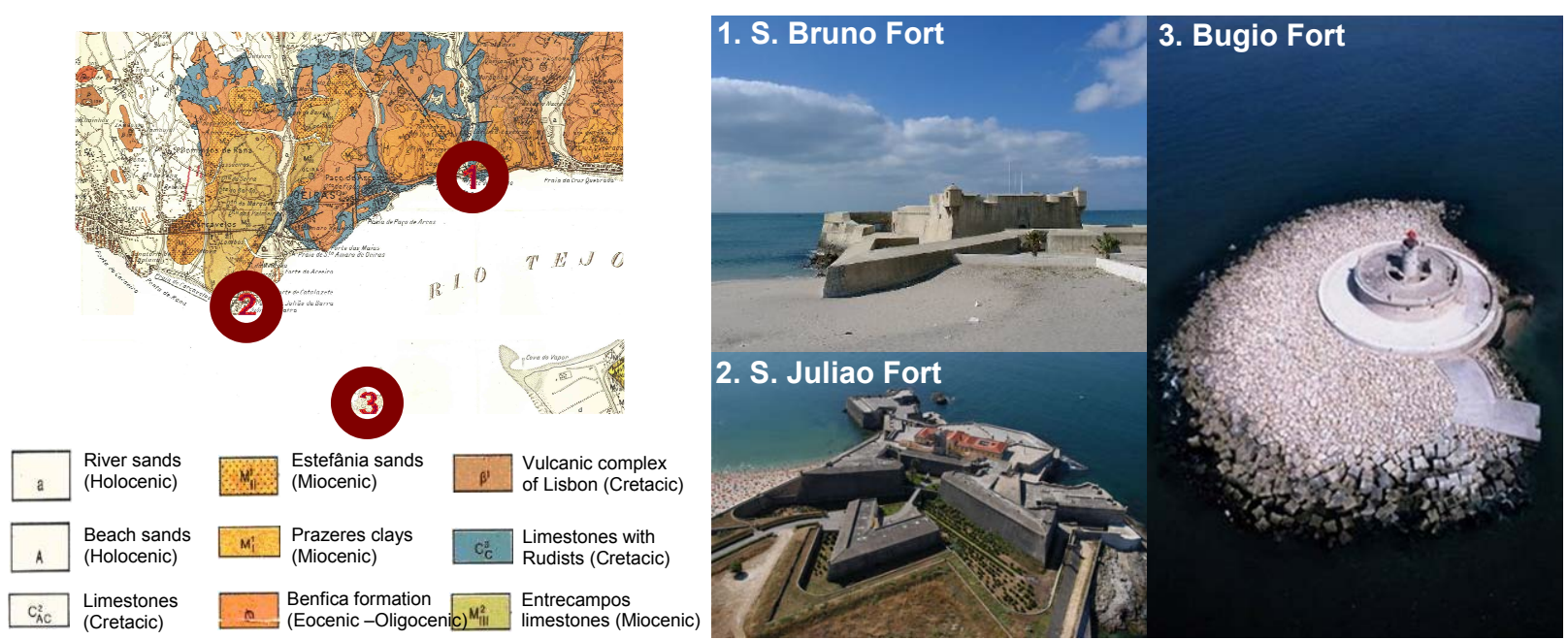

Figure 1. Map of Tagus River fortifications and view of the studied fortifications.

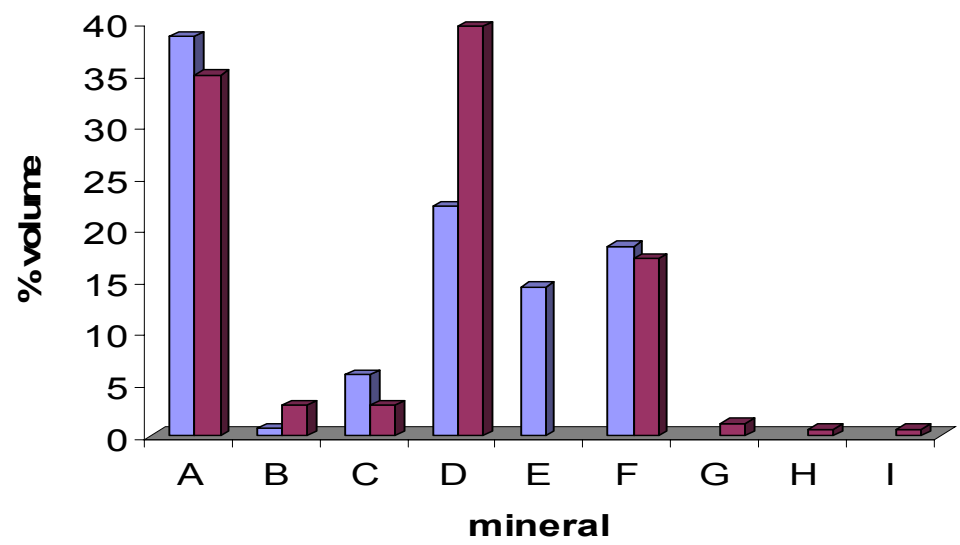

A - lime binder

$B$ - neoformation compounds

$\mathrm{C}-$ lime nodules

$\mathrm{D}$ - quartz

$\mathrm{E}$ - altered quartz

$\mathrm{F}$ - carbonates

$\mathrm{G}$ - feldspars

$\mathrm{H}-$ mica

I - phyllosilicates

$\square$ S. Bruno

$\square$ S. Julião

Figure 2. Quantitative results from point counting by optical microscopy.

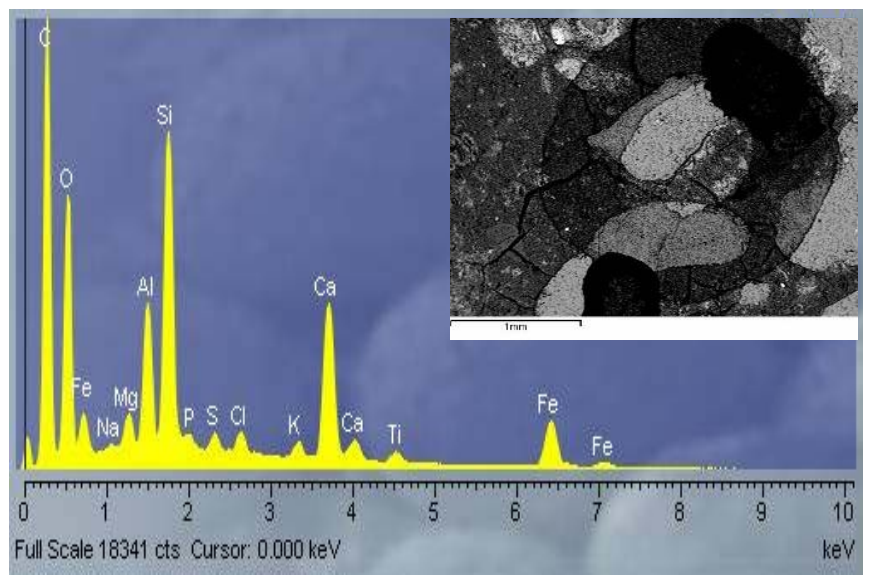

Figure 3 SEM-EDS image and spectrum of neoformation material located at the binder/aggregate interface. 

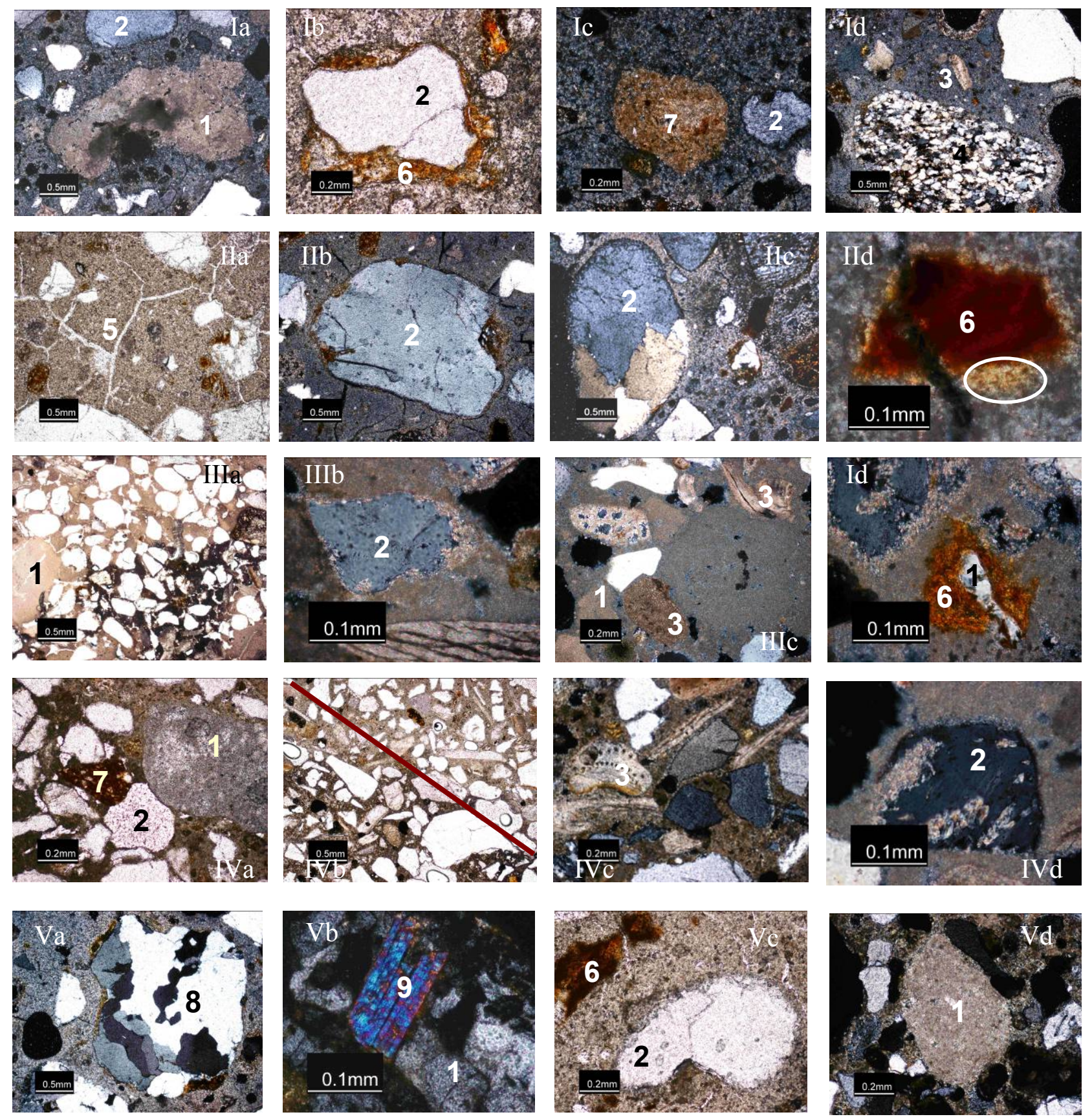

Figure 4. Micrographs from Tagus River 16th and 17th century fortifications mortars. Fort of Bugio: from Ia to IId; Fort of S. Bruno: from IIIa to IIId; Fort de S. Juliao: IVa to Vd. 1-Lime nodule. 2- Quartz grain; 3-shell or fossil; 4-Sandstone; 5-Fracture in binder, filled with secondary carbonate; 6-Neoformation pozzolanic material; 7-Cereamic fragment; 8 Quartzite fragment; 9-Moscovite. 